\title{
The effect of COVID-19 pandemic on life quality of dental professionals
}

\author{
๑Dda Arat Maden', @Buğra Özen², @Ceyhan Altun² \\ ${ }^{1}$ Sariyer Oral and Dental Health Center, Department of Pediatric Dentistry, İstanbul, Turkey \\ ${ }^{2}$ İstanbul Health and Technology University, Faculty of Dentistry, Department of Pediatric Dentistry, İstanbul, Turkey
}

Cite this article as: Arat Maden E, Özen B, Altun C. The effect of COVID-19 pandemic on life quality of dental professionals. J Health Sci Med 2022; 5(1): 274-281.

\begin{abstract}
Introduction: The coronavirus disease of 2019 (COVID-19) pandemic has become the most challenging issue for dental professionals all over the world. The majority of epidemiological reports focus on quality of life and health of general health care workers during the COVID-19 pandemic. In this study, it was aimed to assess the effects of the pandemic on dental professionals' quality of life.

Material and Method: After the vaccination of healthcare workers in Turkey during the COVID-19 pandemic, a descriptive cross-sectional study of 487 dental professionals was carried out by the researchers. Short Form-36 (SF-36) which is based on eight dimensions of health were used to assess dental professionals' quality of life. The data was collected using an electronic questionnaire distributed online. The participants were asked to indicate their socio-demographic data, their practices regarding the COVID-19 pandemic and whether they had contracted the COVID-19 disease.

Results: The quality of life of all participants was moderately disrupted during the COVID-19 pandemic with a mental health score of $51.32( \pm 20.66)$ and a physical health score of $72.9( \pm 16.73)$. Participants who had case tracing duty during the COVID-19 pandemic scored lower with $45.83( \pm 20.08)$ in mental health and $66.94( \pm 18.47)$ in physical health. Overall, COVID-19 pandemic has a serious impact on the quality of life and and this impact is more marked in dental professionals with fewer years of experience and those who had case tracing duty during the COVID-19 pandemic.

Conclusion: The results confirm the need to pay attention to the health of dental professionals who had case tracing duty during the COVID-19 pandemic. The results also point out that dental professionals who are recent graduates and working in the public sector may be more likely to have well-being problems due to the COVID-19 pandemic.
\end{abstract}

Keywords: COVID-19, dental professionals, health concerns, life quality

\section{INTRODUCTION}

Since the first COVID-19 confirmed case was diagnosed in December 2019 in Wuhan, China, all aspects of life have been influenced worldwide (1). This disease is caused by severe acute respiratory syndrome coronavirus 2 (SARSCoV-2), and its transmission can occur after close contact with infected individuals via their body fluids and the respiratory droplets and aerosols (2). Dental treatment can create large amounts of aerosols and droplets mixed with the patient's saliva or blood (3). Since SARSCoV-2 is detected in the saliva of infected individuals, this poses a risk to dentists (4). The oral mucosa has been accepted as a high-risk route of transmission for COVID-19, limiting dental activities to treat urgent and emergency procedures to minimize the production of drops or sprays (5). Dental professionals are concerned about contamination, not only for themselves but also for their families and colleagues. Dentists in many countries had to stop working during the quarantine period until notice stating otherwise. However, they also have had major concerns about the financial consequences of a lockdown (6). Isolation and its financial impact led to physical and psychological pressure, and mental health $(\mathrm{MH})$ problems in dental professionals (5). Besides, due to insufficient number of healthcare providers (HCPs) and the large number of patients, the leaves of many members of medical staff were canceled, and some oral health providers were given extended shifts where some of them had to work in case tracing. In the fight against the COVID-19 pandemic in Turkey, dental professionals were assigned to screen suspected cases, provide consultation, and 
conduct swabs, and played a major role in controlling the epidemic. During this pandemic, a combination of the burden brought about by the pandemic and changes in the daily work routine may have caused poor quality of life to the dental professionals in Turkey.

There are studies in the literature measuring the psychological effects of the COVID-19 pandemic period on healthcare workers $(7,8-11)$. In these studies, it has been shown that the mental health of healthcare professionals is adversely affected due to factors such as long working hours, the risk of disease transmission and transmission to the close circle of friends and family, uncertainties regarding the pandemic, and duties carried out with additional personal protective equipment (8). There are studies showing that all these events cause reluctance to go to work and even leave the profession (12). Healthcare workers have become more susceptible to contracting the disease, as they have to continue their duties while the uncertainty about the epidemic continues. This uncertainty negatively affects mental health and general health. It is therefore reasonable to assume that the health consequences of the pandemic are not limited to those directly related to havig the infection (13).

The majority of research on the effect of COVID-19 infection on dentistry has been focused on practice of dentistry and the measures for the prevention of COVID-19. Only a few studies have evaluated the effects of the COVID-19 outbreak on life quality of dental professionals. Knowledge on the psychological impact of the pandemic on dental personnel is important both to facilitate the optimal treatment of patients as well as the psychological wellbeing of professionals. However, studies investigating the COVID-19 outbreak related concerns and emotional reactions among dental staff from different countries and populations are still required (13). Therefore, the aim of the present study was to explore the factors that influence the physical and psychological impact among dental professionals in relation to background characteristics; their work situation, years of practice, extended shifts like case tracing, and whether having contracted COVID-19 before being vaccinated.

\section{MATERIAL AND METHOD}

For this study, permission was obtained from the COVID-19 Scientific Research Evaluation Commission established under the Ministry of Health, General Directorate of Health Services. Ethical permission required for the study to be carried out was obtained from Gaziosmanpaşa Training and Research Hospital, Medical Researchs Local Ethics Committee (Date: 17.03.2021, Decision No: 2021-243). All procedures were carried out in accordance with the ethical rules and the principles of the Declaration of Helsinki.
This report is based on a questionnaire conducted from March 26 to April 26, 2021, among 487 Turkish dental professionals including those doing post-graduation studies, working in government, private and other health sectors. No setting or location was determined for the study since it was carried out online. Since it is impossible to reach the whole poulation, the lowest number of dental professionals to be included in the study and the sample size were calculated as a minimum of 398 when $\alpha=0.05$, effect size $=0.25$ and the power of the test was 0.80 by the power analysis before the study.

A questionnaire was designed with guidance from the relevant sources and based on experts' opinions (attending dental professionals). It includes 12 questions aimed at obtaining information about the socio-demographic and occupational characteristics of the participants. The questionnaire form used in the study consists of two parts. In the first part, the descriptive and occupational characteristics of the participants such as age, gender, specialty and the unit they work in, health conditions (symptoms/signs relative to the COVID-19 flu), working condition, and knowledge and self-perceived risk of infection were included. In the second part, the Short Form36 (SF-36), a survey was used to evaluate the quality of life of dental professionals. A brief introduction was presented at the beginning of the survey to inform the respondents of the purpose and content of this study, and electronic informed consent was obtained as to whether they agreed to complete the questionnaire. The dental professionals were asked to participate in the study via the internet (e-mail or social media) and were asked to distribute the survey among other colleagues at their convenience. Altough 610 participants were invited to take part in the survey, 487 of them completed the questionnaires, which resulted in a response rate of $79.8 \%$.

\section{Short Form 36 (SF-36) Life Quality Scale}

It is an individual assessment scale developed by Ware et al., in 1987 to examine the general population in the monitoring of health policies in clinical practices and research (14). The Turkish validity study of the scale was conducted in 2018 by Bilir and İçağasığlu (15). This survey had 36 items for evaluating the status of the aspects related to physical and mental health. The main aspect of physical health had 4 subgroups, i.e., physical functioning, pain, general health and limitations due to physical health. Limitations due to emotional problems, emotional well-being, social functioning, and energy/ fatigue were the subgroups included in the mental health aspect of quality of life. The parts assessing physical and mental health were scored separately from 0 to 100 . Lower scores indicated severe impairment and higher scores represented better functions in each item. Increasing scores indicate good quality of life (15). 


\section{Statistical Analysis}

All data were transferred from Google forms into Microsoft Excel (Microsoft Corp, Redmond, WA) and analyzed with IBM SPSS Statistics 22 (SPSS IBM, Turkey). The suitability of the parameters to the normal distribution was evaluated by Kolmogorow-Smirnov and Shapiro Wilks test. While evaluating the study data, in addition to descriptive statistical methods (mean, standard deviation, frequency), Kruskal Wallis test was used in the comparison of more than two groups of parameters in comparison of quantitative data and Dunn's test was used to determine the group that caused the difference. Mann Whitney U test was used for comparisons of parameters between the two groups. Person correlation analysis was used in examining the relationship between the parameters conforming to the normal distribution, and Spearman's

\begin{tabular}{|c|c|c|}
\hline & $\begin{array}{l}\text { Min.- } \\
\text { Max. }\end{array}$ & Me. \pm S.D. \\
\hline \multirow[t]{2}{*}{ Age } & $20-75$ & $37.41 \pm 11.76$ \\
\hline & $\mathbf{n}$ & $\%$ \\
\hline \multicolumn{3}{|l|}{ Gender $(n=486)$} \\
\hline Male & 149 & 30.7 \\
\hline Female & 337 & 69.3 \\
\hline \multicolumn{3}{|l|}{ Age $(n=484)$} \\
\hline $20-29$ & 180 & 37.2 \\
\hline $30-39$ & 110 & 22.7 \\
\hline 40 and over & 194 & 40.1 \\
\hline \multicolumn{3}{|l|}{ Work sector $(n=485)$} \\
\hline Private dental office & 132 & 27.2 \\
\hline Private dental polyclinic & 114 & 23.5 \\
\hline Private dental hospital & 17 & 3.5 \\
\hline State university & 132 & 27.2 \\
\hline Foundation university & 50 & 10.3 \\
\hline Govermental oral and dental health center & 30 & 6.2 \\
\hline Other official institutions & 10 & 2 \\
\hline \multicolumn{3}{|l|}{ Years of experience $(n=484)$} \\
\hline $1-5$ & 181 & 37.4 \\
\hline $6-10$ & 70 & 14.5 \\
\hline $11-15$ & 34 & 7 \\
\hline $16-20$ & 48 & 9.9 \\
\hline $21-30$ & 95 & 19.6 \\
\hline 30 and over & 56 & 11.6 \\
\hline \multicolumn{3}{|l|}{ Title $(n=485)$} \\
\hline Dentists (Dt) & 163 & 33.6 \\
\hline Research assistant (Phd) & 138 & 28.5 \\
\hline Specialist & 44 & 9.1 \\
\hline Doctor & 48 & 9.9 \\
\hline Assistant professors & 53 & 10.9 \\
\hline Associate professor & 39 & 8 \\
\hline \multicolumn{3}{|l|}{ Speciality $(n=460)$} \\
\hline Oral and Maxillofacial Surgery & 11 & 2.4 \\
\hline Oral and Maxillofacial Radyology & 4 & 0.9 \\
\hline Endodontics & 14 & 3 \\
\hline Orthodontics & 16 & 3.5 \\
\hline Periodontology & 7 & 1.5 \\
\hline Prosthetic dentistry & 8 & 1.7 \\
\hline Restorative dentistry & 8 & 1.7 \\
\hline Pediatric Dentistry & 261 & 56.7 \\
\hline No Specialization/PhD & 128 & 27.8 \\
\hline
\end{tabular}

rho correlation analysis was used in examining the relationship between the parameters not conforming to normal distribution. Significance was assessed at the $\mathrm{p}<0.05$ level.

\section{RESULTS}

Overall, 487 dental professionals filled the questionnaire. Among all the participants, 149 (\%30.7) were male, and 337 (\%69.3) were female. The average age was $37.41 \pm 11.76$ years. Background characteristics of respondents were given in Table 1.

9.8\% of the participants have had COVID-19. Fatigue (89.4\%) and headache $(53.2 \%)$ were the most common symptoms related to COVID-19 (Table 2). $72.6 \%$ of dental professionals cared for all patients, $24.7 \%$ only cared for emergency patients, and $2.7 \%$ did not admit any patients. While $8.2 \%$ of the participants had extra shifts like case tracing during the COVID-19 pandemic whereas $91.8 \%$ did not. While $92.4 \%$ believe that the infection caused by COVID-19 is a risk to the dentist, $0.6 \%$ do not believe this and $7 \%$ partially believe such a thing (Table 2).

\begin{tabular}{|c|c|c|}
\hline & $\mathbf{n}$ & $\%$ \\
\hline \multicolumn{3}{|l|}{ Contracting the COVID-19 disease $(\mathrm{n}=482)$} \\
\hline Yes & 47 & 9.8 \\
\hline No & 435 & 90.2 \\
\hline \multicolumn{3}{|l|}{ Symptoms } \\
\hline Yes & 440 & 90.3 \\
\hline No & 47 & 9.7 \\
\hline \multicolumn{3}{|l|}{ Symptoms $(\mathrm{n}=47)$} \\
\hline Fever & 13 & 27.7 \\
\hline Cough & 17 & 36.2 \\
\hline Fatigue & 42 & 89.4 \\
\hline Short Breath & 14 & 29.8 \\
\hline Nasal congestion & 12 & 25.5 \\
\hline Headache & 25 & 53.2 \\
\hline Rhinorrhea & 5 & 10.6 \\
\hline Sore throat & 14 & 29.8 \\
\hline Widespread pain & 18 & 38.3 \\
\hline Diarrhea & 12 & 25.5 \\
\hline Conjunctivitis & 5 & 10.6 \\
\hline \multicolumn{3}{|l|}{ Emergency patients only $(n=485)$} \\
\hline Yes & 120 & 24.7 \\
\hline No & 352 & 72.6 \\
\hline I do not accept any patients & 13 & 2.7 \\
\hline \multicolumn{3}{|l|}{ Case tracing during Covid-19 pandemic $(\mathrm{n}=485)$} \\
\hline Yes & 40 & 8.2 \\
\hline No & 445 & 91.8 \\
\hline \multicolumn{3}{|c|}{$\begin{array}{l}\text { Believing that infection by COVID-19 is a risk to the dentist } \\
(\mathrm{n}=486)\end{array}$} \\
\hline Yes & 449 & 92.4 \\
\hline No & 3 & 0.6 \\
\hline Partially & 34 & 7 \\
\hline \multicolumn{3}{|c|}{$\begin{array}{l}\text { Confident that being infected with COVID-19 can be avoided } \\
\text { during the study }(\mathrm{n}=484)\end{array}$} \\
\hline I am not confident & 268 & 55.4 \\
\hline I am confident enough & 92 & 19 \\
\hline I'm a little confident & 98 & 20.2 \\
\hline I think I can be protected with the vaccine & 26 & 5.4 \\
\hline
\end{tabular}


The minimum, maximum, mean, standard deviation and median values of the sub-dimensions of the quality of life scale are as seen in Table 3. In the relationship between gender and quality of life; physical aspect, mental aspect and SF-36 overall scores of female dental professionals were significantly higher than those of males' ( $\mathrm{p}: 0.001 ; \mathrm{p}<0.05)$. In the relationship between age and quality of life, there was a positive, $12.3 \%$, and statistically significant relationship between age and physical aspect score values ( $\mathrm{p}: 0.007 ; \mathrm{p}<0.05)$. There was a positive, $31.6 \%$, and statistically significant relationship between age and mental aspect score values ( $\mathrm{p}: 0.000 ; \mathrm{p}<0.05)$. There was a positive, $25.6 \%$, and statistically significant relationship between age and SF-36 general score (p:0.000; $\mathrm{p}<0.05)$. The physical aspect scores of dental professionals aged between 20 and 29 were significantly lower than the scores of dental professionals aged betweenn 30 and 39 and those aged 40 and over (p1:0.001; p2:0.000; $\mathrm{p}<0.05)$. Mental aspect scores of dental professionals over 40 years of age were significantly higher than those of dental professionals aged 20-29 and 30-39 years (p1:0.000; p2:0.004; $\mathrm{p}<0.05)$.

Table 3. Minimum, maximum, mean, standard deviation and median values of the sub-dimension scores of the quality of life (SF-36) scale

\begin{tabular}{|c|c|c|c|c|}
\hline & Min. & Max. & Me. \pm S.D. & Median \\
\hline Physical functioning & 0 & 100 & $85 \pm 17.54$ & 90 \\
\hline $\begin{array}{l}\text { Limitations due to } \\
\text { physical health }\end{array}$ & 0 & 100 & $65.5 \pm 38.17$ & 75 \\
\hline Pain & 22 & 90 & $73.56 \pm 16.15$ & 74 \\
\hline General health & 25 & 100 & $67.54 \pm 16.01$ & 67 \\
\hline Energy/fatigue & 0 & 95 & $42.36 \pm 19.87$ & 40 \\
\hline Social functioning & 0 & 100 & $52.26 \pm 29.57$ & 50 \\
\hline Emotional well-being & 0 & 100 & $49.9 \pm 40.96$ & 33.33 \\
\hline $\begin{array}{l}\text { Limitations due to } \\
\text { emotional problems }\end{array}$ & 12 & 100 & $60.74 \pm 17.77$ & 64 \\
\hline Physical aspect & 17.75 & 97.5 & $72.9 \pm 16.73$ & 77.25 \\
\hline Mental aspect & 8 & 94.75 & $51.32 \pm 20.66$ & 50.08 \\
\hline SF-36 General & 20.94 & 96.13 & $62.11 \pm 16.77$ & 61.73 \\
\hline
\end{tabular}

There was a statistically significant difference between the SF-36 general scores of the dental professionals according to the institution they work at ( $\mathrm{p}: 0.000$; $\mathrm{p}<0.05)$. SF-36 general scores of dental professionals working in a private dental office were significantly higher than the scores of dental professionals working in foundation universities and other institutions ( $\mathrm{p} 1: 0.048 ; \mathrm{p} 2: 0.003 ; \mathrm{p}<0.05)$. SF-36 general scores of dentists working in a private dental polyclinic were significantly higher than those of dental professionals working in other institutions ( $\mathrm{p}: 0.009 ; \mathrm{p}<0.05)$.
There was a statistically significant difference between SF-36 general scores of the dental professionals according to years of experience ( $\mathrm{p}: 0.000 ; \mathrm{p}<0.05)$. SF-36 general scores of dental professionals with an experience of 1-5 years were significantly lower than the scores of dental professionals with with an experience of 6-10 years, 1620 years, 21-30 years and more than 30 years (p1:0.004; p2:0.000; p3:0.000; 4 4:0.000; $\mathrm{p}<0.05)$.

There was no statistically significant difference between the fields of specialization in terms of SF-36 general scores $(p>0.05)$. In the COVID-19 pandemic, the physical aspect scores and SF-36 general scores of the dental professionals who were on case tracing duty were statistically significantly lower than those of the dental professionals who were not ( $\mathrm{p}: 0.025 ; \mathrm{p}<0.05)$.

In the study, it was found that the SF-36 overall scores of those who think that they can be protected from COVID-19 with vaccination were statistically significantly higher than those who were not confident that they can avoid COVID-19 and those who were a little confident in doing so (p1:0.000; $\mathrm{p} 2: 0.002 ; \mathrm{p}<0.05)$. Moreover, it could be concluded from the study that the SF-36 overall scores of those who were not confident in avoiding COVID-19 were statistically significantly lower than those who were sufficiently confident and a little confident ( $\mathrm{p} 1: 0.000 ; \mathrm{p} 2: 0.021 ; \mathrm{p}<0.05)$.

\section{DISCUSSION}

To the best of our knowledge, this study is the first of its kind to focus on the quality of life in dental health professionals during the recent COVID-19 outbreak. We present this data on general quality of life disruptions to provide evidence on the health of dental professionals during this COVID-19 crisis. However, most studies on quality of life during the COVID-19 pandemic have been conducted among frontline health care workers, and more studies among dental professionals are required.

Although the well-being and emotional resilience of healthcare workers are essential components of maintaining health services during the COVID-19 pandemic, it has been observed that healthcare workers experience serious psychological problems and are at risk for mental health during this period (16). A recent survey reported an increased risk of depression, anxiety, and insomnia especially among female HCPs during the emergence of COVID-19, prompting psychological preventive measures or interventions (17).

The COVID-19 pandemic put a pressure on all dental healthcare professionals and has affected the delivery of dental health care services globally (13). Today, the mental health and physical well-being of dental professionals has been significantly affected by COVID-19 outbreak in various aspects. 
The results showed that, age, work sector, years of experience, having case tracing duty during the COVID-19 pandemic, confidency that being infected with COVID-19 can be avoided during the study, title and gender variables significantly predicted dental healthcare workers' quality of life. Older age, more years of practice, confidency that being infected with COVID-19 can be avoided during the study and being a male heightened psychological and physical resilience while being a research assistant and having case tracing duty during the COVID-19 pandemic lowered psychological resilience.

Global medical human resources are limited. As a result, many hospital-based health care workers have had to work out of hours and take on extra shifts like case tracing.
These types of stressors have been associated with poor quality of life (18). Zhao et al. (19) showed that medical staff members in China who had close contact with COVID-19 patients had much higher levels of anxiety and depression when compared with their counterparts who had no contact. Close contact with COVID-19 patients was also shown to negatively affect the medical staff's quality of life (19). Shacham et al. (20) identified psychological distress among dentists and found that the fear of getting infected with COVID-19 from a patient provides high psychological tension. Similarly, in this study, the quality of life of dental professionals who had case tracing duty and had close contact with COVID-19 patients was negatively affected.

\begin{tabular}{|c|c|c|c|}
\hline & $\begin{array}{c}\text { Physical aspect } \\
\text { Me. } \pm \text { S.D. (median) }\end{array}$ & $\begin{array}{c}\text { Mental aspect } \\
\text { Me. } \pm \text { S.D. (median) }\end{array}$ & $\begin{array}{c}\text { SF-36 General } \\
\text { Me. } \pm \text { S.D. (median) }\end{array}$ \\
\hline \multicolumn{4}{|l|}{ Gender } \\
\hline Male & $75.6 \pm 15.33(79.8)$ & $56.08 \pm 19.79(56.5)$ & $65.84 \pm 15.95(67.1)$ \\
\hline Female & $71.76 \pm 17.2(76)$ & $49.28 \pm 20.71(47.9)$ & $60.52 \pm 16.88(59.8)$ \\
\hline p1 & $0.025^{*}$ & $0.001^{*}$ & $0.001^{\star}$ \\
\hline \multicolumn{4}{|l|}{ Age } \\
\hline $20-29$ & $69.15 \pm 15.69(72)$ & $43.71 \pm 18.42(40.1)$ & $56.43 \pm 15.07(56.4)$ \\
\hline $30-39$ & $75.5 \pm 15.89(79.8)$ & $50.61 \pm 20.02(50.3)$ & $63.05 \pm 16.16(62.8)$ \\
\hline 40 and over & $74.88 \pm 17.61(82.3)$ & $58.77 \pm 20.45(62.5)$ & $66.83 \pm 17.13(70.8)$ \\
\hline p2 & $0.000^{*}$ & $0.000^{*}$ & $0.000^{*}$ \\
\hline \multicolumn{4}{|l|}{ Work sector } \\
\hline Private dental office & $75.58 \pm 17.16(82)$ & $55.84 \pm 21.71(59.6)$ & $65.71 \pm 17.11(68.9)$ \\
\hline Private dental polyclinic & $76.08 \pm 13.87(77)$ & $53.57 \pm 20.37(52.7)$ & $64.82 \pm 15.24(65.5)$ \\
\hline Private dental hospital & $68.4 \pm 18.21(69.8)$ & $45.35 \pm 23.88(39.8)$ & $56.87 \pm 19.58(60.7)$ \\
\hline State university & $71.94 \pm 16.77(75.5)$ & $49.35 \pm 19.64(48.3)$ & $60.65 \pm 16.85(61)$ \\
\hline Foundation university & $69.69 \pm 17.01(75.6)$ & $45.51 \pm 17.84$ & $57.6 \pm 14.39(58.7)$ \\
\hline Govermental oral and dental health center & $67.65 \pm 17.68(72.8)$ & $48.44 \pm 21.3(44)$ & $58.05 \pm 18.11(57)$ \\
\hline \multirow[t]{2}{*}{ Others } & $53.75 \pm 15.66(50.9)$ & $38.42 \pm 8.15(38.5)$ & $46.09 \pm 8.68(46.1)$ \\
\hline & $0.000^{*}$ & $0.007^{*}$ & $0.000^{*}$ \\
\hline \multicolumn{4}{|l|}{ Years of experience } \\
\hline $1-5$ & $68.56 \pm 15.81(70.5)$ & $43.36 \pm 17.99(40)$ & $55.96 \pm 14.9(56.1)$ \\
\hline $6-10$ & $76.68 \pm 14.79(79.4)$ & $52.16 \pm 20.24(49.2)$ & $64.42 \pm 15.21(62.8)$ \\
\hline $11-15$ & $75.08 \pm 17.21(82.3)$ & $48.35 \pm 21.72(52.5)$ & $61.72 \pm 18.48(66.1)$ \\
\hline $16-20$ & $76.43 \pm 16.77(83)$ & $56.59 \pm 20.04(57.2)$ & $66.51 \pm 16.66(70.4)$ \\
\hline $21-30$ & $73.59 \pm 18.2(80.3)$ & $59.71 \pm 19.73(64.4)$ & $66.65 \pm 16.73(68.8)$ \\
\hline 30 and over & $76.84 \pm 16.74(83.3)$ & $59.98 \pm 21.23(63.8)$ & $68.41 \pm 17.75(73.3)$ \\
\hline p2 & $0.000^{*}$ & $0.000^{*}$ & $0.000^{*}$ \\
\hline \multicolumn{4}{|l|}{ Title } \\
\hline Dentists (Dt) & $73.27 \pm 17.71(79.8)$ & $54.94 \pm 21.18(58.5)$ & $64.11 \pm 17.5(67.7)$ \\
\hline Research assistant (Phd) & $69.38 \pm 16(72.8)$ & $43.47 \pm 18.23(40.9)$ & $56.42 \pm 14.86(57)$ \\
\hline Specialist & $73.84 \pm 16.97(75.6)$ & $52.39 \pm 21.2(52.9)$ & $63.11 \pm 17.91(62.8)$ \\
\hline Doctor & $78.92 \pm 13.16(82.5)$ & $55.61 \pm 22.51(57.6)$ & $67.26 \pm 16.21(68)$ \\
\hline Assistant professors & $72.96 \pm 17.66(76.5)$ & $49.41 \pm 19.24(48.6)$ & $61.18 \pm 16.69(63.9)$ \\
\hline Associate professor & $75.37 \pm 15.51(81.8)$ & $60.4 \pm 17.17(63.3)$ & $67.89 \pm 14.38(65.9)$ \\
\hline $\mathrm{p} 2$ & $0.008^{\star}$ & $0.000^{*}$ & $0.000^{*}$ \\
\hline \multicolumn{4}{|l|}{ Speciality } \\
\hline Oral and Maxillofacial Surgery & $73.59 \pm 19.54(84)$ & $51.33 \pm 2474(57.8)$ & $62.46 \pm 20.65(68.5)$ \\
\hline Endodontics & $77.98 \pm 20.88(87)$ & $48.4 \pm 23.71(38.4)$ & $63.19 \pm 18.04(62.7)$ \\
\hline Orthodontics & $74.2 \pm 21.07(80.6)$ & $47.2 \pm 21.49(44.2)$ & $60.7 \pm 18.25(61.2)$ \\
\hline Periodontology & $83.71 \pm 8.11(82.3)$ & $68.67 \pm 23.84(79.8)$ & $76.19 \pm 13.56(76.5)$ \\
\hline Prosthetic dentistry & $76.63 \pm 18.92(85)$ & $67.25 \pm 21.33(76.8)$ & $71.94 \pm 19.85(82.3)$ \\
\hline Restorative dentistry & $60.69 \pm 23.8(57.1)$ & $43.5 \pm 24.69(43.8)$ & $52.09 \pm 23.26(46.5)$ \\
\hline Pediatric Dentistry & $72.75 \pm 15.02(75.5)$ & $49.14 \pm 19.1(48.3)$ & $60.94 \pm 15.41(61)$ \\
\hline No Specialization/PhD & $72.58 \pm 18.07(79.4)$ & $54.29 \pm 21.79(53.9)$ & $63.44 \pm 17.71(65.3)$ \\
\hline $\mathrm{p} 2$ & 0.152 & $0.028^{*}$ & 0.089 \\
\hline
\end{tabular}




\begin{tabular}{|c|c|c|c|}
\hline & $\begin{array}{c}\text { Physical aspect } \\
\text { Me. } \pm \text { S.D. (median) }\end{array}$ & $\begin{array}{c}\text { Mental aspect } \\
\text { Me. } \pm \text { S.D. (median) }\end{array}$ & $\begin{array}{c}\text { SF-36 General } \\
\text { Me. } \pm \text { S.D. (median) }\end{array}$ \\
\hline \multicolumn{4}{|l|}{ Contracting the COVID-19 disease } \\
\hline Yes & $70.91 \pm 19.92(77.3)$ & $54.55 \pm 21.44(57.5)$ & $62.73 \pm 18.59(64.3)$ \\
\hline No & $73.07 \pm 16.35(77.3)$ & $51.16 \pm 20.55(50.1)$ & $62.12 \pm 16.61(61.7)$ \\
\hline p1 & 0.731 & 0.300 & 0.717 \\
\hline \multicolumn{4}{|l|}{ Emergency patients only } \\
\hline Yes & $71.13 \pm 17.03(75.8)$ & $50.43 \pm 18.44(49.6)$ & $60.78 \pm 16.29(61.1)$ \\
\hline No & $73.44 \pm 16.46(77.8)$ & $51.48 \pm 21.43(49.9)$ & $62.46 \pm 16.89(62.2)$ \\
\hline I do not receive any patients & $75.15 \pm 21.25(86)$ & $53.93 \pm 17.43(54.3)$ & $64.54 \pm 17.37(71.1)$ \\
\hline $\mathrm{p} 2$ & 0.226 & 0.868 & 0.694 \\
\hline \multicolumn{4}{|l|}{ Case tracing during COVID-19 pandemic } \\
\hline Yes & $66.94 \pm 18.47(70.4)$ & $45.83 \pm 20.08(43.9)$ & $56.39 \pm 17.62(56)$ \\
\hline No & $73.53 \pm 16.46(77.8)$ & $51.91 \pm 20.65(52)$ & $62.72 \pm 16.59(62.7)$ \\
\hline p1 & $0.025^{\star}$ & 0.065 & $0.027^{\star}$ \\
\hline \multicolumn{4}{|c|}{ Believing that infection by COVID-19 is a risk to the dentist } \\
\hline Yes & $72.41 \pm 17.07(76.5)$ & $51.23 \pm 20.81(50.2)$ & $61.82 \pm 17.05(61.7)$ \\
\hline Partially & $78.57 \pm 9.95(81.9)$ & $50.18 \pm 16.62(47.3)$ & $64.38 \pm 11.04(62.5)$ \\
\hline p1 & 0.133 & 0.774 & 0.514 \\
\hline \multicolumn{4}{|c|}{ Confidency that being infected with COVID-19 can be avoided during the study } \\
\hline I am not confident & $70.25 \pm 18.03(74.5)$ & $48.73 \pm 19.65(48)$ & $59.49 \pm 16.93(59.7)$ \\
\hline I am confident enough & $78.05 \pm 13.18(81.4)$ & $57.77 \pm 20.76(61.9)$ & $67.91 \pm 14.73(69.3)$ \\
\hline I'm a little confident & $73.74 \pm 14.72(75.1)$ & $50.61 \pm 19.63(49.9)$ & $62.18 \pm 15.23(62.4)$ \\
\hline I think I can be protected with the vaccine & $83.71 \pm 13.21(88)$ & $67.73 \pm 20.97(76.4)$ & $75.72 \pm 15.33(80.6)$ \\
\hline 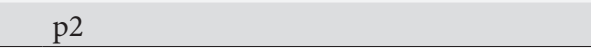 & $0.000^{*}$ & $0.000^{*}$ & $0.000^{*}$ \\
\hline
\end{tabular}

The findings of this survey suggest that almost all the dentists were experiencing some form of mental health symptoms and stress because of changes in their daily work routine due to the pandemic situation in Turkey. In a previous study in the UK, statistically significant associations between the mental health and stress levels of dentists were discovered due to work-related changes implemented to reduce the transmission of the virus during the peak of the pandemic (21). In the letter study, dentists who were not working had more anxiety and depressive symptoms compared with the working group. Although both places of work (independent and public sector) had a statistically significant risk of poor $\mathrm{MH}$, dentists working in the public sector were less affected and had reduced odds of developing $\mathrm{MH}$ symptoms (21). In the study conucted with healthcare workers, Așkın Ceran et al., revealed no statistically significant difference between the SF-36 scale mean scores according to the work sector of dental professionals' work during the COVID-19 pandemic (22). Unlike, the study carried out by Askin Ceran et al., in this study, it was found that dentists in the private dental office had statistically significant mental health scores compared with those in the public sector. This could be attributed to the large number of dental patients visiting the public centers per day in comparison to private clinics (23). Working in an independent sector seemed to have a protective effect for quality of life. Morever, in this study, no significant difference was found between life quality and mental health scores of dental professionals who examined all of the patients, those who examined only emergency patients and those who did not examine any patients.

It was found that socio-demographic characteristics of dental professionals such as age and gender affected SF36 scores in this study. The SF-36 scale mean score and, mental and physical health scores of male participants were significantly higher than those of female patients. Unlike our research findings, in a study conducted by $\mathrm{Su}$ etal. in Taiwan, no statistically significant difference was observed between the SF-36 scale mean scores of female and male participants $(\mathrm{p}=0.21)(24)$. Also, Aşkın Ceran et al., reported that there was no statistically significant difference between the SF-36 scale mean scores according to gender (22).

Dental professionals' work experience had an impact on instability, infection and concerns. Dental professionals with longer working experience were less likely to report fear of changes in the work-environment (heavy workload), fear of being infected and infecting (13). On the other hand, to the results of this study, we found that dental professionals with the shortest working experience (1-5 years) had the lowest SF-36 mean for mental and physical health scores. 
In addition, it was observed that there was no statistically significant difference between the SF-36 scale mean scores of those who were infected with COVID-19 and not infected with COVID-19 during the pandemic ( $\mathrm{p}>0.05)$. It was revealed that contracting the COVID-19 disease did not affect the SF-36 scale mean scores.

\section{Limitations}

The study has certain limitations. First of all, this study was based on a cross-sectional observation survey. We also do not know whether this lower quality of life existed before COVID-19. Similarly, online self-assessment questionnaires may be affected by the difficulty of completing them. This could affect the validity of the data provided.

\section{CONCLUSION}

The present study showed a considerable psychological impact of the COVID-19 pandemic on dental professionals in Turkey regardless of working clinically with patients or not. Promoting the mental health and life quality of all dental professionals should be a critical part of the public health response, and specific efforts should be directed to sensitive sectors. Dental professionals must take measures to make this unending experience as bearable as possible, and public health officials must act cautiously and be more attentive to sectors that seem to have been forgotten. Strategies to prevent and support the stressed dentists will help the dental profession in the long term.

\section{ETHICAL DECLARATIONS}

Ethics Committee Approval: The study was carried out with the permission of Gaziosmanpaşa Training and Research Hospital, Medical Researchs Local Ethics Committee (Date: 17.03.2021, Decision No: 2021-243).

Informed Consent: The electronic informed consent was obtained if the participants agreed to complete the questionnaire.

Referee Evaluation Process: Externally peer-reviewed.

Conflict of Interest Statement: The authors have no conflicts of interest to declare.

Financial Disclosure: The authors declare that this study has received no financial support.

Author Contributions: All of the authors declare that they have all participated in the design, execution, and analysis of the paper and that they have approved the final version.

Acknowledgments: The authors thank the dentists who took part in the study for their participation in the study. Furthermore, the authors would like to thank the entire board of the Turkish Society of Dentistry for their kind support.

\section{REFERENCES}

1. Huang C, Wang Y, Li X, et al. Clinical features of patients with 2019 novel coronavirus in Wuhan, China. Lancet 2020; 395: 497506.

2. Öztürk R. Exploring healthcare professionals' views and approaches regarding COVID-19 vaccines. J Health Sci Med 2021; 4: 692-7.

3. Harrel SK, Molinari J. Aerosols and splatter in dentistry: a brief review of the literature and infection control implications. J Am Dent Assoc 2004; 135: 429-37.

4. Azzi L, Carcano G, Gianfagna F, et al. Saliva is a reliable tool to detect SARS-CoV-2. J Infect 2020; 81: e45-e50.

5. Vergara-Buenaventura A, Chavez-Tuñon M, Castro-Ruiz C. The mental health consequences of coronavirus disease 2019 pandemic in dentistry. Disaster Med Public Health Prep 2020; 14: e31-e34.

6. Coulthard P. Dentistry and coronavirus (COVID-19)-moral decision-making. Br Dent J 2020; 228: 503-5.

7. Khanna RC, Honavar SG, Metla AL, Bhattacharya A, Maulik PK. Psychological impact of COVID-19 on ophthalmologistsin-training and practising ophthalmologists in India. BMC Ophthalmol 2020; 68: 994-8.

8. Uzun N, Tekin M, Sertel E, Tuncar A. Psychological and social effects of COVID-19 pandemic on obstetrics and gynecology employees. J Surg Med 2020; 4: 355-8.

9. Bohlken J, Schömig F, Lemke MR, Pumberger M, Riedel-Heller SG. COVID-19-Pandemie: Belastungen des medizinischen Personals [COVID-19 Pandemic: Stress Experience of Healthcare Workers A Short Current Review]. Psychiatr Prax 2020; 47: 190-7.

10. Consolo U, Bellini P, Bencivenni D, Iani C, Checchi V. Epidemiological aspects and psychological reactions to COVID-19 of dental practitioners in the Northern Italy Districts of Modena and Reggio Emilia. Int J Environ Res Public Health 2020; 17: 3459.

11.Temsah MH, Al-Sohime F, Alamro N, et al. The psychological impact of COVID-19 pandemic on health care workers in a MERS-CoV endemic country. J Infect Public Health 2020; 13: 877-82.

12.Lai J, Ma S, Wang Y, et al. Factors associated with mental health outcomes among health care workers exposed to coronavirus disease 2019. JAMA Netw Open 2020; 3: e203976.

13. Uhlen MM, Ansteinsson VE, Stangvaltaite-Mouhat L, et al. Psychological impact of the COVID-19 pandemic on dental health personnel in Norway. BMC Health Serv Res 2021; 21: 420.

14. Ware JE Jr, Sherbourne CD. The MOS 36-item short-form health survey (SF-36). I. Conceptual framework and item selection. Med Care 1992; 30: 473-83.

15. Bilir Kaya B, İçağasıoğlu A. Reliability and validity of the Turkish version of short form 36 (SF-36) in patients with rheumatoid. J Surg Med 2018; 2: 11-6.

16.Bozdağ F, Ergün N. Psychological resilience of healthcare professionals during COVID-19 pandemic. Psychol Rep 2020; 13: 33294120965477.

17. Vafaei H, Roozmeh S, Hessami K, et al. Obstetrics Healthcare Providers' Mental Health and Quality of Life During COVID-19 Pandemic: Multicenter Study from Eight Cities in Iran. Psychol Res Behav Manag 2020; 13: 563-71.

18. Caruso CC. Negative impacts of shiftwork and long work hours. Rehabil Nurs 2014; 39: 16-25.

19.Zhao S, Cao J, Sun R, Zhang L, Liu B. Analysis of anxiety-related factors amongst frontline dental staff during the COVID-19 pandemic in Yichang, China. BMC Oral Health 2020; 20: 342. 
20.Shacham M, Hamama-Raz Y, Kolerman R, Mijiritsky O, BenEzra M, Mijiritsky E. COVID-19 factors and psychological factors associated with elevated psychological distress among dentists and dental hygienists in Israel. Int J Environ Res Public Health 2020; 17: 2900.

21. Ranka MS, Ranka SR. Survey of mental health of dentists in the COVID-19 pandemic in the UK. J Int Soc Prev Community Dent 2021; 11: 104-8.

22. Askın Ceran M, Tanrıkulu G, Turker E, Tanrıkulu Y. Determination of the effect of COVID-19 pandemic on the anxiety levels and life quality of healthcare workers. Marmara Med J 2021; 34: 189-94.

23. Fernández-Feijoo J, Garea-Gorís R, Fernández-Varela M, TomásCarmona I, Diniz-Freitas M, Limeres-Posse J. Prevalence of systemic diseases among patients requesting dental consultation in the public and private systems. Med Oral Patol Oral Cir Bucal 2012; 17: e89-93.

24. Su TP, Lien TC, Yang CY, et al. Prevalence of psychiatric morbidity and psychological adaptation of the nurses in a structured SARS caring unit during outbreak: a prospective and periodic assessment study in Taiwan. J Psychiatr Res 2007; 41: 119-30. 